\title{
PENERAPAN DISTRIBUTION REQUIREMENT PLANNING (DRP) PADA CENTRAL WAREHOUSE PT. COCA COLA AMATIL BOTTLE PANDAAN
}

\section{Annisa Kesy Garside ${ }^{1}$}

\begin{abstract}
This research has a good to plan the product delivery schedule from central ware house to each ware house and from ware house to PT. Coca Cola outlet to minimize the holding number of product. To plan this schedule we implement DRP ( Distribution Requirement Planning ) method. With using the product demand data, lead time of delivery, holding cost and release cost, also BOD ( Bill Of Distribution ). Then analysis them using DRP software to find the shipping schedule. After implementing DRP method PT. Coca Cola can decrease about RP 7.205.761.500,00 for 8 weeks.
\end{abstract}

\section{Key Words : Distribution Requirement Planning, software, schedule}

\section{PENDAHULUAN}

\section{PT Coca-Cola Amatil Indonesia} adalah perusahaan yang menangani seluruh kegiatan operasional dan distribusi produk Coca-cola di seluruh Indonesia. Perusahaan ini membawahi 12 (duabelas) pabrik yang tersebar di pulau Jawa, Sumatra, Kalimantan dan Sulawesi. Produk yang dihasilkan oleh pabrik-pabrik tersebut terdiri dari Coca-Cola, Sprite dan Fanta dalam kemasan botol (RGB), botol plastik (PET) dan kaleng (CAN). Di pulau Jawa sendiri terdapat 16 warehouse yang terletak di 4 (empat) region. Sebagai salah satu produk minuman ringan yang paling terkenal di dunia, PT Coca-Cola Amatil Indonesia jelas membutuhkan penanganan distribusi dan persediaan yang baik agar tidak tertinggal dari pesaingnya. Para analis sering menyatakan, kemenangan Coca-Cola atas pesaingnya lebih diakibatkan oleh jaringan distribusi yang kuat untuk merangkul konsumen mengambang yang tidak mengenal brand loyalty (Teguh, P, Majalah Swasembada No.05. / XIV hal 54-56, 1998 ).

Jaringan PT Coca-Cola Amatil Indonesia yang begitu luas mengakibatkan banyak permasalahan pada sistem distribusinya. Masing-masing warehouse melayani kebutuhan konsumen yang berbeda dan memiliki luas penampungan yang berbeda pula sehingga kapasitas pendistribusian barang dari masing-masing warehouse juga harus diperhitungkan agar tidak terjadi lost sale maupun kelebihan barang pada warehouse yang bisa mengakibatkan terjadinya banyak hal misalnya terjadinya penumpukan barang bisa berakibat banyak barang yang rusak dan tidak layak untuk dikonsumsi serta pembengkakan holding cost. Untuk itu akan dicoba penerapan Distribution Requirement Planning untuk mengoptimalkan ketersediaan barang dan mencegah terjadinya lost sale pada

1) Dosen Jurusan Teknik Industri Fakultas Teknik Universitas Mubammadiyah Malang 
masing-masing warehouse di PT Coca-Cola Amatil Indonesia .

\section{TINJAUAN PUSTAKA}

\section{Distribution Requirements Planning.}

Distribution Requirements Planning berfungsi menentukan kebutuhan-kebutuhan untuk mengisi kembali inventory pada branch warehouse (synonym: distribution centre). Dengan DRP, ketergantungan atau hubungan diantara stocking points/locations dalam struktur jaringan distribusi ditunjukkan oleh suatu Bill Of Distribution dan memiliki konsep yang serupa dengan Bill of Material dalam MRP.

\section{Logika Dasar Distribution Requirement Planning}

Distribution Requirement planning (DRP) adalah metode untuk menangani pengadaan persediaan dalam suatu jaringan distribusi multi eselon. Aktivitas DRP meliputi :

- Netting.

Netting adalah proses untuk mencari jumlah kebutuhan bersih yang didapat dari kebutuhan kotor dikurangi dengan projected On Hand ( $\mathrm{POH}$ ) atau barang yang ada di gudang.

- Lot sizing

Merupakan penentuan kapasitas lot atau jumlah pengadaan barang. Dalam menggunakan metode lot sizing yang tepat ada parameter tertentu yang dipergunakan antara lain jarak pengangkutan dari central warehouse ke masing - masing warehouse, ordering cost dan holding cost Adapun metode lot sizing yang sering dipergunakan adalah sebagai berikut : Economic Order Quantity (EOQ),Lot For Lot ( L4L ), Least Unit Cost ( LUC ), Least Total Cost ( LTC ), dan Economic Production Quantity (EPQ).

- Time Phasing

Time phasing atau biasa disebut dengan

offsetting merupakan proses untuk menentukan kapan order akan dilakukan.

Waktu order ditentukan dengan mengurangi due date dengan planning lead time-nya

- Explotion

Merupakan proses perhitungan kebutuhan kotor untuk item atau komponen pada level dibawahnya yang disesuaikan dengan Bill Of Distribution-nya ( BOD ).

Untuk lebih mengetahui lebih lanjut tentang langkah - langkah pengerjaan DRP adalah sebagai berikut :

Dari hasil ramalan di gudang cabang dihitung net requirement ( NR ) dengan cara :

$\mathrm{NR}=($ Gross Requirement $\quad(\mathrm{GR})+$ Safety stock) - ( Scheduled Receipts $+\quad$ Projected On Hand ( $\mathrm{POH}$ ) periode sebelumnya )

NR terjadi bila tingkat stock ( TS ) lebih kecil dari safety stock.

$\mathrm{TS}=$ Scheduled receipts $+\mathrm{POH}-\mathrm{GR}$ 
Dari perhitungan pada no 1 diperoleh Planned order receipts untuk memenuhi NR pada periode yang bersangkutan. Langkah 2 diatas akan menentukan saat planned order release (hari/saat pengiriman) dengan menggunakan informasi lead time.

Projected on hand pada akhir setiap periode dapat dihitung dengan rumusan sbb :

$\mathrm{POH}_{\mathrm{t}}=\left(\mathrm{POH}_{\mathrm{t}-1}+\right.$ Scheduled receipts + planned order release ) - GR

Planned order release akan menjadi GR pada periode yang sama untuk pusat pengiriman (level gudang yang lebih tinggi). Jadi dapat di jelaskan bahwa peramalan pada demand historis dilakukan pada masing - masing gudang atau tingkat distribusi yang paling bawah dan kemudian DRP dapat dilakukan dengan metode pull system (dari tingkat distribusi level bawah ke tingkat distribusi yang paling atas berdasarkan Bill of Distribution-nya).

\section{METODOLOGI PENELITIAN}

\section{Pengumpulan Data}

Data-data yang dibutuhkan adalah sebagai berikut :

1. Data demand pada masing-masing warehouse dan outlet.

2. Barang dalam perjalanan : Barang dalam perjalanan digunakan untuk mengetahui jumlah barang yang seharusnya bisa diterima pada periode yang telah ditetapkan sebelumnya (schedule receipt).

3. Persediaan barang dalam gudang baik pada central warehouse (pabrik) maupun pada masing-masing warehouse: data ini digunakan untuk mengetahui berapa barang yang saat ini ada di tangan (projected on hand).

4. Kapasitas gudang (dalam satuan krat dan $\mathrm{kg}$ ) pada masing-masing warehouse dan outlet.

5. Rencana Pengangkutan: Data ini diperlukan untuk memastikan berapa lama lead time yang dibutuhkan oleh central warehouse untuk mengirimkan barang ke masing - masing warehouse.

6. Biaya simpan dan pesan pada masingmasing warehouse dan outlet

\section{Pembuatan Program}

Program dibuat dengan menggunakan bahasa pemrograman $\mathrm{C}$ dimana bahasa ini sangat kompatibel. Selanjutnya sebelum Software ini digunakan terlebih dahulu akan diuji coba kemampuannya dengan membandingkan hasil software dengan hasil perhitungan manual.

\section{Pengolahan Data}

1. Forecasting / peramalan

Peramalan adalah langkah awal untuk memulai DRP. Untuk menemukan suatu metode peramalan yang terbaik sehingga meminimasi kesalahan peramalan yang dijadikan sebagai acuan adalah Mean 
Absolute Precentage Error (MAPE) yaitu rata-rata persentase kesalahan absolut. Dalam penelitian ini, peramalan dibantu dengan menggunakan software Quantitatif System (QS).

\section{Lot Sizing}

Lot Sizing dilakukan untuk menentukan berapa jumlah lot yang sesuai dengan kapasitas dan bisa meminimumkan holding cost dan ordering cost. Banyak sekali metode-metode yang bisa dipakai dalam Lot sizing. Penentuan lot didasarkan pada jarak angkut, holding cost, ordering cost dan lain sebagainya.Kalkulasi lot sizing dilakukan dengan menggunakan software yang telah dibuat. Begitu program DRP dijalankan maka akan terlihat menu menu khusus yang memungkinkan kita untuk memilih metode yang tepat untuk lot sizing pada masing - masing warehouse dan outlet.

\section{Lead time}

Lead time merupakan jarak waktu pemesanan dengan waktu yang dibutuhkan. Lead time ditentukan oleh kebijakan perusahaan. Selama ini perusahaan menggunakan lead time selama 1 ( satu ) minggu.

\section{Penerapan DRP dengan aplikasi komputer}

Input dari DRP meliputi hasil forecasting , data barang dalam perjalanan, barang dalam gudang, dan waktu yang dipakai dalam distribusi untuk menetapkan lead time yang digunakan. Input lain dalam DRP adalah safety stock dan reorder point. Kedua hal ini sangat penting dalam proses pengadaan barang. Kalkulasi safety stock dan reorder point dilakukan secara otomatis dengan software yang telah dibuat.

Hasil dari DRP adalah berupa jumlah lot yang sesuai dengan kebutuhan dan rencana pengiriman yang nantinya menghasilkan jadwal induk distribusi .

\section{Kapasitas Pengangkutan}

Hasil dari DRP yang merupakan rencana pengiriman di tinjau kembali apakah sesuai dengan kapasitas pengangkutan dan kapasitas warehouse atau tidak, apabila melebihi kapasitas pengangkutan maka perlu adanya peninjauan kembali pada pengolahan datanya. Kelebihan pada kapasitas pengangkutan bisa diakibatkan dari kesalahan peramalan, jumlah lot yang kurang tepat dan lain sebagainya.

\section{Perbandingan biaya sebelum dan sesudah diterapkannya DRP.}

Untuk mengetahui bahwa DRP berhasil diterapkan di perusahaan maka perlu adanya suatu perbandingan cost baik itu holding cost maupun ordering cost-nya. Sehingga kita bisa membuktikan bahwa DRP ini benar - benar efektif diterapkan di PT Coca - Cola Amatil Indonesia yang memiliki jaringan multi eselon. 


\section{HASIL DAN PEMBAHASAN}

Setelah dilakukan pengolahan data kemudian memasukkan pada program DRP diperoleh rencana jadwal distribusi selama 8 minggu kedepan antara bulan Juli sampai dengan akhir agustus 2001. Dimana rencana jadwal tersebut dilakukan untuk semua produk yang dihasilkan oleh PT. Coca Cola yaitu Coke, Fanta dan Sprite mulai dari ukuran small, medium maupun liter, dengan pertimbangan agar biaya simpan dan pesan sebelum dan sesudah penerapan DRP dapat dihitung serta dapat melihat kelayakan penerapan hasil DRP ditinjau dari kapasitas warehouse dan pengangkutan. Hasil dari DRP untuk rencana distribusi untuk produk minuman Coke adalah sebagai berikut

Tabel 1

Produk : Coke Small

\section{Hasil kalkulasi DRP}

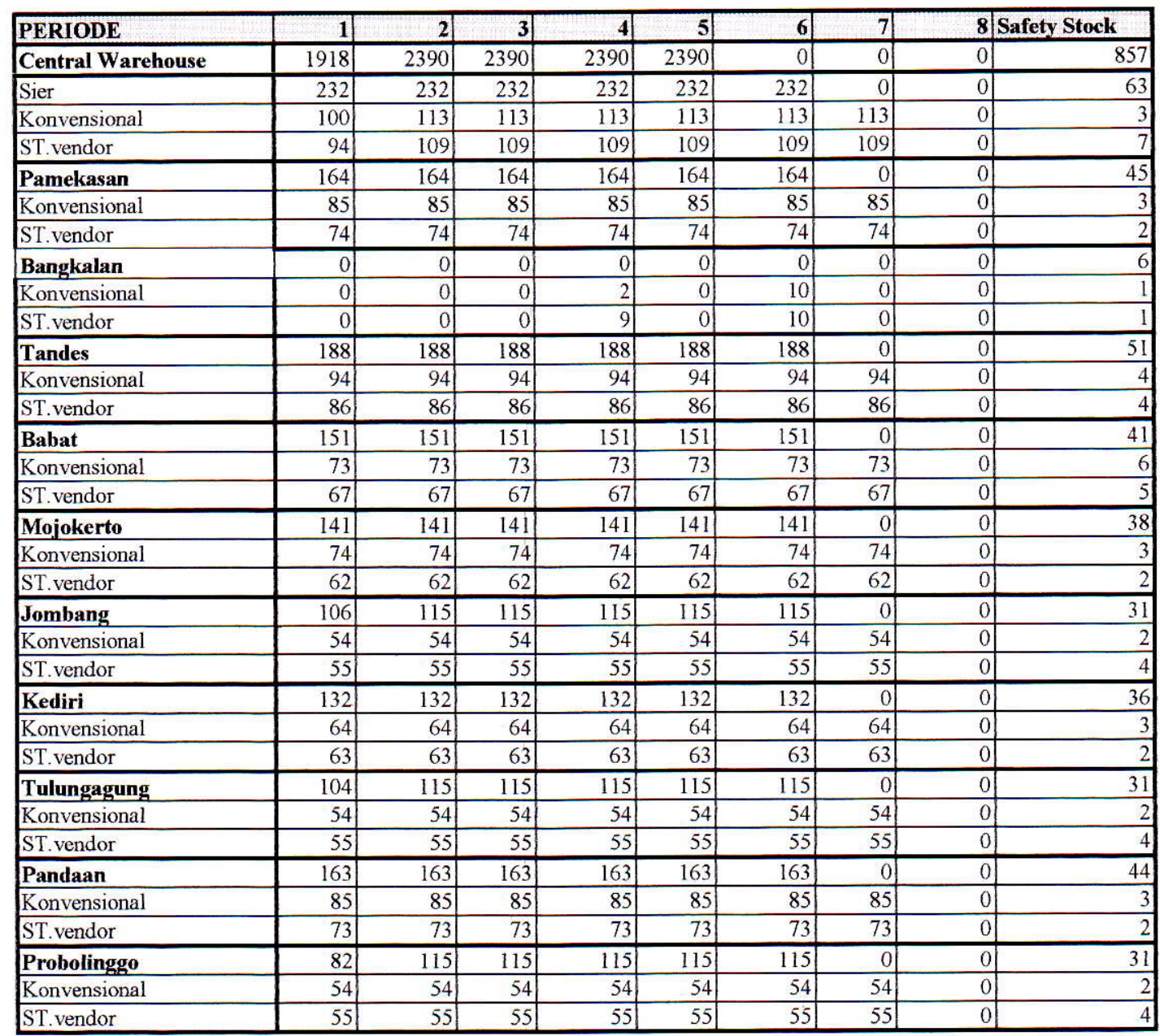




\begin{tabular}{|l|r|r|r|r|r|r|r|r|r|}
\hline Situbondo & 0 & 0 & 0 & 0 & 0 & 0 & 0 & 0 & \\
\hline Konvensional & 0 & 10 & 0 & 10 & 0 & 10 & 0 & 0 & 8 \\
\hline ST.vendor & 0 & 10 & 0 & 10 & 0 & 10 & 0 & 0 & 1 \\
\hline Jember & 123 & 132 & 132 & 132 & 132 & 132 & 0 & 0 & 1 \\
\hline Konvensional & 64 & 64 & 64 & 64 & 64 & 64 & 64 & 0 & 36 \\
\hline ST.vendor & 63 & 63 & 63 & 63 & 63 & 63 & 63 & 0 & 3 \\
\hline Banyuwangi & 0 & 0 & 0 & 0 & 0 & 0 & 0 & 0 & 2 \\
\hline Konvensional & 0 & 0 & 0 & 10 & 0 & 10 & 0 & 0 & 7 \\
\hline ST.vendor & 0 & 0 & 0 & 5 & 0 & 10 & 0 & 0 & 1 \\
\hline Malang & 232 & 232 & 232 & 232 & 232 & 232 & 0 & 0 & 1 \\
\hline Konvensional & 113 & 113 & 113 & 113 & 113 & 113 & 113 & 0 & 63 \\
\hline ST.vendor & 109 & 109 & 109 & 109 & 109 & 109 & 109 & 0 & 3 \\
\hline Kepanjen & 0 & 0 & 0 & 0 & 0 & 0 & 0 & 0 & 7 \\
\hline Konvensional & 0 & 0 & 0 & 6 & 0 & 10 & 0 & 0 & 6 \\
\hline ST.vendor & 0 & 0 & 0 & 5 & 0 & 10 & 0 & 0 & 1 \\
\hline
\end{tabular}

\section{Produk : Coke Medium}

\begin{tabular}{|c|c|c|c|c|c|c|c|c|c|}
\hline PERIODE & 1 & 2 & 3 & 4 & 5 & 6 & 7 & 8 & Safety Stock \\
\hline Central Warehouse & 2580 & 2580 & 2580 & 2580 & 2595 & 0 & 0 & 0 & 922 \\
\hline Sier & 249 & 249 & 249 & 249 & 249 & 249 & 0 & 0 & 68 \\
\hline Konvensional & 111 & 111 & 111 & 111 & 111 & 111 & 111 & 0 & 7 \\
\hline ST.vendor & 126 & 126 & 126 & 126 & 126 & 126 & 126 & 0 & 5 \\
\hline Pamekasan & 188 & 188 & 188 & 188 & 188 & 188 & 0 & 0 & 51 \\
\hline Konvensional & 88 & 88 & 88 & 88 & 88 & 88 & 88 & 0 & 4 \\
\hline ST.vendor & 92 & 92 & 92 & 92 & 92 & 92 & 92 & 0 & 4 \\
\hline Bangkalan & 0 & 0 & 0 & 0 & 0 & 9 & 0 & 0 & 6 \\
\hline Konvensional & 8 & 9 & 9 & 9 & 9 & 9 & 9 & 0 & 2 \\
\hline \begin{tabular}{|l|} 
ST.vendor \\
\end{tabular} & 0 & 7 & 8 & 8 & 8 & 8 & 8 & 0 & 2 \\
\hline Tandes & 241 & 241 & 241 & 241 & 241 & 241 & 0 & 0 & 66 \\
\hline Konvensional & 115 & 115 & 115 & 115 & 115 & 115 & 115 & 0 & 5 \\
\hline ST.vendor & 118 & 118 & 118 & 118 & 118 & 118 & 118 & 0 & 3 \\
\hline Babat & 182 & 182 & 182 & 182 & 182 & 182 & 0 & 0 & 50 \\
\hline Konvensional & 86 & 86 & 86 & 86 & 86 & 86 & 86 & 0 & 2 \\
\hline ST.vendor & 90 & 90 & 90 & 90 & 90 & 90 & 90 & 0 & 4 \\
\hline Mojokerto & 153 & 153 & 153 & 153 & 153 & 153 & 0 & 0 & 42 \\
\hline Konvensional & 76 & 76 & 76 & 76 & 76 & 76 & 76 & 0 & 2 \\
\hline ST.vendor & 72 & 72 & 72 & 72 & 72 & 72 & 72 & 0 & 3 \\
\hline Jombang & 56 & 88 & 88 & 88 & 88 & 88 & 0 & 0 & 24 \\
\hline Konvensional & 58 & 58 & 58 & 58 & 58 & 58 & 58 & 0 & 3 \\
\hline ST.vendor & 24 & 24 & 24 & 24 & 24 & 24 & 24 & 0 & 3 \\
\hline Kediri & 146 & 146 & 146 & 146 & 146 & 146 & 0 & 0 & 40 \\
\hline Konvensional & 76 & 76 & 76 & 76 & 76 & 76 & 76 & 0 & 3 \\
\hline ST.vendor & 64 & 64 & 64 & 64 & 64 & 64 & 64 & 0 & 3 \\
\hline Tulungagung & 48 & 88 & 88 & 88 & 88 & 88 & 0 & 0 & 24 \\
\hline Konvensional & 58 & 58 & 58 & 58 & 58 & 58 & 58 & 0 & 3 \\
\hline ST.vendor & 20 & 24 & 24 & 24 & 24 & 24 & 24 & 0 & 3 \\
\hline Pandaan & 188 & 188 & 188 & 188 & 188 & 188 & 0 & 0 & 51 \\
\hline Konvensional & 88 & 88 & 88 & 88 & 88 & 88 & 88 & 0 & 4 \\
\hline ST.vendor & 92 & 92 & 92 & 92 & 92 & 92 & 92 & 0 & 4 \\
\hline Probolinggo & 21 & 88 & 88 & 88 & 88 & 88 & 0 & 0 & 24 \\
\hline Konvensional & 58 & 58 & 58 & 58 & 58 & 58 & 58 & 0 & 3 \\
\hline ST.vendor & 24 & 24 & 24 & 24 & 24 & 24 & 24 & 0 & 3 \\
\hline \begin{tabular}{|l|} 
Situbondo \\
\end{tabular} & 18 & 21 & 21 & 21 & 21 & 21 & 0 & 0 & 5 \\
\hline Konvensional & 9 & 9 & 9 & 9 & 9 & 9 & 9 & 0 & 2 \\
\hline ST.vendor & 8 & 8 & 8 & 8 & 8 & 8 & 8 & 0 & 2 \\
\hline
\end{tabular}




\begin{tabular}{|l|r|r|r|r|r|r|r|r|r|}
\hline Jember & 137 & 146 & 146 & 146 & 146 & 146 & 0 & 0 & 40 \\
\hline Konvensional & 76 & 76 & 76 & 76 & 76 & 76 & 76 & 0 & 3 \\
\hline ST.vendor & 64 & 64 & 64 & 64 & 64 & 64 & 64 & 0 & 3 \\
\hline Banyuwangi & 0 & 0 & 0 & 0 & 0 & 0 & 0 & 0 & 6 \\
\hline Konvensional & 4 & 9 & 9 & 9 & 9 & 9 & 9 & 0 & 2 \\
\hline ST.vendor & 0 & 6 & 8 & 8 & 8 & 8 & 8 & 0 & 2 \\
\hline Malang & 249 & 249 & 249 & 249 & 249 & 249 & 0 & 0 & 68 \\
\hline Konvensional & 111 & 111 & 111 & 111 & 111 & 111 & 111 & 0 & 7 \\
\hline ST.vendor & 126 & 126 & 126 & 126 & 126 & 126 & 126 & 0 & 5 \\
\hline Kepanjen & 0 & 0 & 0 & 0 & 0 & 0 & 0 & 0 & 0 \\
\hline Konvensional & 7 & 9 & 9 & 9 & 9 & 9 & 9 & 0 & 5 \\
\hline ST.vendor & 8 & 8 & 8 & 8 & 8 & 8 & 8 & 0 & 2 \\
\hline
\end{tabular}

\section{Produk : Coke Liter}

\begin{tabular}{|c|c|c|c|c|c|c|c|c|c|}
\hline PERIODE & 1) & 2 & 3 & 4 & 5 & 6 & 7 & 8 & Safety Stock \\
\hline Central Warehouse & 0 & 0 & 598 & 1040 & 1040 & 0 & 0 & 0 & 369 \\
\hline Sier & 83 & 94 & 94 & 94 & 94 & 94 & 0 & 0 & 25 \\
\hline Konvensional & 42 & 42 & 42 & 42 & 42 & 42 & 42 & 0 & 6 \\
\hline ST.vendor & 42 & 42 & 42 & 42 & 42 & 42 & 42 & 0 & 4 \\
\hline Pamekasan & 50 & 77 & 77 & 77 & 77 & 77 & 0 & 0 & 21 \\
\hline Konvensional & 36 & 36 & 36 & 36 & 36 & 36 & 36 & 0 & 4 \\
\hline ST.vendor & 33 & 33 & 33 & 33 & 33 & 33 & 33 & 0 & 4 \\
\hline Bangkalan & 0 & 0 & 0 & 0 & 0 & 0 & 0 & 0 & 8 \\
\hline Konvensional & 0 & 0 & 0 & 10 & 0 & 10 & 0 & 0 & 2 \\
\hline ST.vendor & 0 & 6 & 0 & 10 & 0 & 10 & 0 & 0 & 2 \\
\hline Tandes & 70 & 86 & 86 & 86 & 86 & 86 & 0 & 0 & 23 \\
\hline Konvensional & 41 & 41 & 41 & 41 & 41 & 41 & 41 & 0 & 3 \\
\hline ST.vendor & 98 & 38 & 38 & 38 & 38 & 38 & 38 & 0 & 4 \\
\hline Babat & 35 & 71 & 71 & 71 & 71 & 71 & 0 & 0 & 19 \\
\hline Konvensional & 33 & 33 & 33 & 33 & 33 & 33 & 33 & 0 & 4 \\
\hline ST.vendor & 31 & 31 & 31 & 31 & 31 & 31 & 31 & 0 & 3 \\
\hline Mojokerto & 22 & 63 & 63 & 63 & 63 & 63 & 0 & 0 & 17 \\
\hline Konvensional & 31 & 31 & 31 & 31 & 31 & 31 & 31 & 0 & 2 \\
\hline ST.vendor & 29 & 29 & 29 & 29 & 29 & 29 & 29 & 0 & 1 \\
\hline Jombang & 0 & 48 & 51 & 51 & 51 & 51 & 0 & 0 & 14 \\
\hline Konvensional & 24 & 24 & 24 & 24 & 24 & 24 & 24 & 0 & 2 \\
\hline ST.vendor & 22 & 22 & 22 & 22 & 22 & 22 & 22 & 0 & 3 \\
\hline Kediri & 2 & 52 & 52 & 52 & 52 & 52 & 0 & 0 & 14 \\
\hline Konvensional & 25 & 25 & 25 & 25 & 25 & 25 & 25 & 0 & 1 \\
\hline ST.vendor & 25 & 25 & 25 & 25 & 25 & 25 & 25 & 0 & 1 \\
\hline Tulungagung & 0 & 50 & 51 & 51 & 51 & 51 & 0 & 0 & 14 \\
\hline Konvensional & 24 & 24 & 24 & 24 & 24 & 24 & 24 & 0 & 2 \\
\hline ST.vendor & 22 & 22 & 22 & 22 & 22 & 22 & 22 & 0 & 3 \\
\hline Pandaan & 34 & 77 & 77) & 77 & 77) & 77 . & 0 & 0 ) & 21 \\
\hline Konvensional & 36 & 36 & 36 & 36 & 36 & 36 & 36 & 0 & 4 \\
\hline ST.vendor & 33 & 33 & 33 & 33 & 33 & 33 & 33 & 0 & 4 \\
\hline Probolinggo & 0 & 51 & 51 & 51 & 51 & 51 & 0 & 0 & 14 \\
\hline Konvensional & 24 & 24 & 24 & 24 & 24 & 24 & $24 \mid$ & 0 & 2 \\
\hline ST.vendor & 22 & 22 & 22 & 22 & 22 & 22 & 22 & 0 & 3 \\
\hline Situbondo & 0 & 0 & 0 & 0 & 0 & 0 & 0 & 0 & 9 \\
\hline Konvensional & 0 & 9 & 0 & 10 & 0 & 10 & 0 & 0 & 2 \\
\hline ST.vendor & 0 & 8 & 0 & 10 & 0 & 10 & 0 & 0 & 2 \\
\hline Jember & 0 & 30 & 52 & 52 & 52 & 52 & 0 & 0 & 14 \\
\hline Konvensional & 25 & 25 & 25 & 25 & 25 & 25 & 25 & 0 & 1 \\
\hline ST.vendor & 25 & 25 & 25 & 25 & 25 & 25 & 25 & 0 & 1 \\
\hline
\end{tabular}




\begin{tabular}{|l|r|r|r|r|r|r|r|r|r|}
\hline Banyuwangi & 0 & 0 & 0 & 0 & 0 & 0 & 0 & 0 & \\
\hline Konvensional & 0 & 10 & 0 & 10 & 0 & 10 & 0 & 0 & 9 \\
\hline ST.vendor & 0 & 10 & 0 & 10 & 0 & 10 & 0 & 0 & 2 \\
\hline Malang & 29 & 94 & 94 & 94 & 94 & 94 & 0 & 0 & 25 \\
\hline Konvensional & 42 & 42 & 42 & 42 & 42 & 42 & 42 & 0 & 6 \\
\hline ST.vendor & 42 & 42 & 42 & 42 & 42 & 42 & 42 & 0 & 4 \\
\hline Kepanjen & 0 & 0 & 0 & 0 & 0 & 0 & 0 & 0 & 9 \\
\hline Konvensional & 0 & 10 & 0 & 10 & 0 & 10 & 0 & 0 & 2 \\
\hline ST.vendor & 0 & 10 & 0 & 10 & 0 & 10 & 0 & 0 & 2 \\
\hline
\end{tabular}

Setelah diperoleh rencana distribusi untuk semua produk maka langkah selanjutnya adalah meninjau apakah hasil DRP melebihi atau tidak kapasitas warehouse dan pengangkutan.

1. Peninjauan kapasitas warehouse.

Selama ini PT.Coca - Cola Amatil telah memiliki data kapasitas masing-masing

Tabel 2

Jumlah barang yang akan dikirim Dari Central Warehouse dalam satuan Krat

\begin{tabular}{|l|r|r|r|r|r|r|r|r|}
\hline Warehouse & 1 & 2 & 3 & 4 & 5 & 6 & 7 & 8 \\
\hline Sier & 2099 & 2144 & 2144 & 2144 & 2144 & 2144 & 0 & 0 \\
\hline Pamekasan & 1578 & 1693 & 1693 & 1693 & 1693 & 1693 & 0 & 0 \\
\hline Bangkalan & 450 & 539 & 611 & 611 & 611 & 620 & 0 & 0 \\
\hline Tandes & 1913 & 1969 & 1969 & 1969 & 1969 & 1969 & 0 & 0 \\
\hline Babat & 1429 & 1569 & 1569 & 1569 & 1569 & 1569 & 0 & 0 \\
\hline Mojokerto & 1223 & 1390 & 1390 & 1390 & 1390 & 1390 & 0 & 0 \\
\hline Jombang & 820 & 1075 & 1088 & 1088 & 1088 & 1088 & 0 & 0 \\
\hline Kediri & 1026 & 1238 & 1239 & 1239 & 1239 & 1242 & 0 & 0 \\
\hline Tulungagung & 864 & 1071 & 1088 & 1088 & 1088 & 1088 & 0 & 0 \\
\hline Pandaan & 1512 & 1692 & 1692 & 1692 & 1692 & 1692 & 414 & 0 \\
\hline Probolinggo & 725 & 1034 & 1088 & 1088 & 1088 & 1088 & 57 & 0 \\
\hline Situbondo & 456 & 557 & 632 & 632 & 632 & 632 & 0 & 0 \\
\hline Jember & 938 & 1175 & 1239 & 1239 & 1239 & 1239 & 0 & 0 \\
\hline Banyuwangi & 405 & 525 & 611 & 611 & 611 & 611 & 41 & 0 \\
\hline Malang & 1958 & 2139 & 2139 & 2139 & 2139 & 2139 & 0 & 0 \\
\hline Kepanjen & 419 & 487 & 603 & 611 & 611 & 611 & 0 & 0 \\
\hline
\end{tabular}

Tabel 3

Kapasitas Warehouse

\begin{tabular}{|l|c|l|c|}
\hline \multicolumn{1}{|c|}{ WAREHOUSE } & KRAT / MINGGU & WAREHOUSE & KRAT / MINGGU \\
\hline REGION I & & & \\
\hline SIER & 157333 & REGION IV & \\
\hline PAMEKASAN & 13643 & PANDAAN & 22346 \\
\hline BANGKALAN & 4744 & PROBOLINGGO & 21879 \\
\hline
\end{tabular}




\begin{tabular}{|l|c|l|c|}
\hline REGION II & & SITUBONDO & 3810 \\
\hline TANDES & 59000 & JEMBER & 18609 \\
\hline BABAT & 31651 & BANYUWANGI & 22985 \\
\hline REGION III & & MALANG & 34416 \\
\hline MOJOKERTO & 13520 & KEPANJEN & 16839 \\
\hline JOMBANG & 14750 & & \\
\hline KEDIRI & 11554 & & \\
\hline TULUNGAGUNG & 17208 & & \\
\hline
\end{tabular}

Dapat dilihat pada tabel diatas bahwa

rencana jumlah barang yang akan dikirim

tidak melebihi kapasitas warehouse pada tiap minggunya.

2. Peninjauan kapasitas pengangkutan.

Kapasitas pengangkutan ditentukan oleh banyaknya angkutan yang tersedia dan berapa kali terjadi pengiriman barang dalam satu periode (delapan minggu). Untuk lebih jelasnya akan kita lihat pada tabel dibawah ini :

Tabel 4

Jumlah Barang yang Akan Dikirim dari Central Warehouse dalam Satuan Krat

\begin{tabular}{|l|r|r|r|r|r|r|r|r|}
\hline Warehouse & $\mathbf{1}$ & $\mathbf{2}$ & $\mathbf{3}$ & $\mathbf{4}$ & $\mathbf{5}$ & $\mathbf{6}$ & $\mathbf{7}$ & $\mathbf{8}$ \\
\hline Sier & 2099 & 2144 & 2144 & 2144 & 2144 & 2144 & 0 & 0 \\
\hline Pamekasan & 1578 & 1693 & 1693 & 1693 & 1693 & 1693 & 0 & 0 \\
\hline Bangkalan & 450 & 539 & 611 & 611 & 611 & 620 & 0 & 0 \\
\hline Tandes & 1913 & 1969 & 1969 & 1969 & 1969 & 1969 & 0 & 0 \\
\hline Babat & 1429 & 1569 & 1569 & 1569 & 1569 & 1569 & 0 & 0 \\
\hline Mojokerto & 1223 & 1390 & 1390 & 1390 & 1390 & 1390 & 0 & 0 \\
\hline Jombang & 820 & 1075 & 1088 & 1088 & 1088 & 1088 & 0 & 0 \\
\hline Kediri & 1026 & 1238 & 1239 & 1239 & 1239 & 1242 & 0 & 0 \\
\hline Tulungagung & 864 & 1071 & 1088 & 1088 & 1088 & 1088 & 0 & 0 \\
\hline Pandaan & 1512 & 1692 & 1692 & 1692 & 1692 & 1692 & 414 & 0 \\
\hline Probolinggo & 725 & 1034 & 1088 & 1088 & 1088 & 1088 & 57 & 0 \\
\hline Situbondo & 456 & 557 & 632 & 632 & 632 & 632 & 0 & 0 \\
\hline Jember & 938 & 1175 & 1239 & 1239 & 1239 & 1239 & 0 & 0 \\
\hline Banyuwangi & 405 & 525 & 611 & 611 & 611 & 611 & 41 & 0 \\
\hline Malang & 1958 & 2139 & 2139 & 2139 & 2139 & 2139 & 0 & 0 \\
\hline Kepanjen & 419 & 487 & 603 & 611 & 611 & 611 & 0 & 0 \\
\hline Jumlah total & 17815 & 20297 & 20795 & 20803 & 20803 & 20815 & 512 & 0 \\
\hline
\end{tabular}


Dan berikut ini adalah tabel kapasitas pengangkutan untuk tiap periode yang disediakan oleh Central warehouse.

\section{Tabel 5}

Kapasitas Pengangkutan Tiap Periode

\begin{tabular}{|l|c|c|c|c|}
\hline $\begin{array}{c}\text { Jenis } \\
\text { Angkutan }\end{array}$ & $\begin{array}{c}\text { Jml } \\
\text { Angkutan }\end{array}$ & $\begin{array}{c}\text { Kapasitas } \\
\text { Angkutan }\end{array}$ & $\begin{array}{c}\text { Jumlah siklus } \\
\text { per periode }\end{array}$ & $\begin{array}{c}\text { Kapasitas total angkutan } \\
\text { per periode }\end{array}$ \\
\hline Troton & 20 & 300 & 6 & 36000 \\
\hline Truck & 5 & 200 & 6 & 6000 \\
\hline Angkle & 15 & 150 & 6 & 13500 \\
\hline Jml barang yang bisa dikirim per periode & & 55500 \\
\hline
\end{tabular}

Keterangan

- Siklus : pemakaian angkutan dari berangkat sampai kembali lagi ke central warehouse

Dari tabel 4 dan 5 diatas dapat diketahui bahwa kapasitas pengiriman barang setiap periode sangat mencukupi, sehingga tidak akan terjadi kekurangan kapasitas pengangkutan setelah diterapkannya DRP.

\section{Perbandingan biaya sebelum dan sesudah diterapkannya DRP.}

1. Biaya sebelum diterapkannya DRP.

Selama ini PT Coca - Cola Amatil Pandaan mensuplai barang sebesar 4 kali lipat dari jumlah permintaan pada tiap minggunya untuk masing-masing warehouse.

Sehingga, total holding cost selama delapan periode equivalent dengan $93 \mathrm{x}$ holding cost selama satu periode dimana $x$ adalah jumlah demand satu periode dan selama delapan periode terjadi tujuh kali pemesanan sehingga: Total cost $=(7$. ordering cost $)+(93$. demand satu periode . holding cost)

Tabel 6

Kalkulasi Total Cost Sebelum Diterapkannya DRP

\begin{tabular}{|l|r|r|r|r|}
\hline & $\begin{array}{c}\text { Demand } \\
\text { (Dlm Krat) }\end{array}$ & $\begin{array}{c}\text { Total ordering } \\
\text { cost } \\
\text { (Dalam Rupiah) }\end{array}$ & $\begin{array}{c}\text { Total holding cost } \\
\text { (Dalam Rupiah ) }\end{array}$ & $\begin{array}{c}\text { Total cost per } \\
\text { warehouse } \\
\text { (Dalam Rupiah) }\end{array}$ \\
\hline Sier & 1059 & 551.250 & 768.198 .600 & 768.749 .850 \\
\hline Pamekasan & 819 & 551.250 & 609.336 .000 & 609.887 .250 \\
\hline Bangkalan & 303 & 551.250 & 281.790 .000 & 282.341 .250 \\
\hline Tandes & 929 & 490.000 & 691.176 .000 & 691.666 .000 \\
\hline Babat & 768 & 490.000 & 535.680 .000 & 536.170 .000 \\
\hline Mojokerto & 698 & 428.750 & 292.113 .000 & 292.541 .750 \\
\hline Jombang & 556 & 428.750 & 258.540 .000 & 258.968 .750 \\
\hline Kediri & 620 & 428.750 & 432.450 .000 & 432.878 .750 \\
\hline Tulungagung & 556 & 428.750 & 232.686 .000 & 233.114 .750 \\
\hline Pandaan & 819 & 367.500 & 685.503 .000 & 685.870 .500 \\
\hline Probolinggo & 556 & 367.500 & 387.810 .000 & 388.177 .500 \\
\hline Situbondo & 303 & 367.500 & 239.521 .500 & 239.889 .000 \\
\hline
\end{tabular}




\begin{tabular}{|l|r|r|r|r|}
\hline Jember & 620 & 367.500 & 553.536 .000 & 553.903 .500 \\
\hline Banyuwangi & 303 & 367.500 & 246.566 .250 & 246.933 .750 \\
\hline Malang & 1059 & 367.500 & 866.685 .600 & 867.053 .100 \\
\hline Kepanjen & 303 & 367.500 & 211.342 .500 & 211.710 .000 \\
\hline \multicolumn{4}{|l}{ Total cost seluruh warehouse } & \\
\hline
\end{tabular}

\section{Keterangan:}

Demand : Total permintaan semua jenis barang (Coke, Sprite, Fanta) dan ukuran (Small, Medium, Liter) pada satu periode.

2. Biaya sesudah diterapkannya DRP.

Penghitungan biaya setelah diterapkan
DRP pada prisipnya sama dengan penghitungan biaya sebelum diterapkannya DRP yaitu:

Total cost $=$ Total holding cost + Total ordering cost

Berdasarkan output program DRP, data yang diperoleh adalah sebagai berikut:

Tabel 7

Kalkulasi Cost Sesudah Diterapkannya DRP

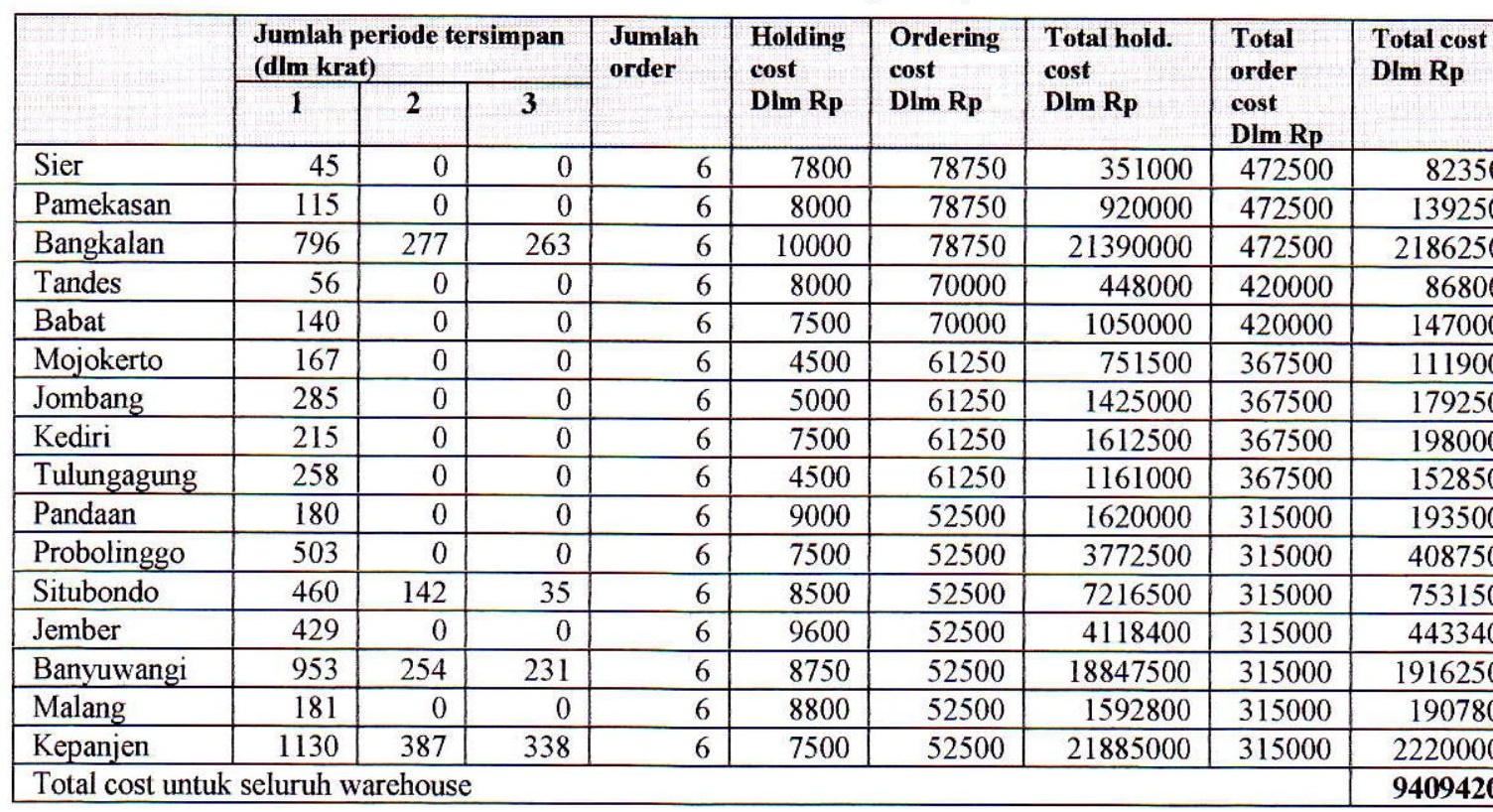

Dari kedua tabel diatas dapat dilihat KESIMPULAN

bahwasannya perusahaan bisa menghemat biaya sebesar Rp. 7.205.761.500 dalam delapan periode ( 8 minggu ).

Dari analisa data maka dapat ditarik kesimpulan sebagai berikut :

1. PT. Coca Cola dapat mengoptimalkan ketersediaan produknya baik di warehouse maupun outlet dengan menerapkan sistem 
DRP, hal ini dibuktikan dengan jumlah persediaan yang selama ini selalu menumpuk dalam jumlah besar di masingmasing outlet dan warehouse sebagai akibat kebijaksanaan pengiriman produk sebesar 4 kali dari jumlah permintaan untuk tiap minggu dapat dikurangi hanya sebesar safety stock yang berfungsi sebagai persediaan pengaman jika terjadi permintaan yang fluktuatif.

2. Dengan Menerapkan sistem DRP, PT. Coca Cola dapat mengetahui kapan harus mengirimkan masing-masing produk dari central warehouse menuju masing-masing warehouse dan dari warehouse menuju masing-masing outlet secara tepat.

3. Dengan menerapkan sistem DRP maka perusahaan bisa menghemat biaya simpan dan pesan sebesar Rp. 7.205.761.500 dalam delapan periode ( 8 minggu ).

\section{DAFTAR PUSTAKA}

Ballau, Ronald. $\mathrm{H}$, Business logistics Management, third edition, PrenticeHall International editions, Englewood cliffs, Newjersey, 1992.

Bedworth, david.j; bailey, james.E, Integrated

\section{Production Control Systems;}

Management Analysis Design, John

Wiley and Sons Inc, Singapore, 1982.

Bowersso.x, Donal. J; Closs,

David.J;Logistical Management, The Integrated Supply Chain Process, Mc. Graw- Hill International edition, Singapore, 1996.
Fogarty, Donald.W; Blackstone; Hoffmann; Production and Inventory Management; 2D edition; SouthWestern Publishing Co, 1991.

Gaspersz, Vincent. Dr, M.St., CQIA, CFPIM; Production Planning and Inventory Control berdasarkan pendekatan sistem terintegrasi MRP II dan JIT menuju Manufakturing 21, kerjasama Vincent Fondation dengan PT. Gramedia Pustaka Utama, Jakarta, 1998.

Silver, Edward. A;Peterson,Rein; Decision System for Inventory, Management and Production Planning, John wiley and Sons Inc, 1979.

Tersine, Richard. J, Principles of Inventory and Material Management, Third Edition, Elsevier Science Publishing Co.Inc, North Holand, 1988.

Teguh, P, Berkelit lewat Kewarganegaraan, Majalah Swasembada No.05. / XIV hal $54-56,1998$. 